\title{
An experimental case-conference programme for obstetrics and gynaecology clinical students
}

\author{
Henk ten Have and Gerard Essed Maastricht, The Netherlands
}

\section{Author's abstract}

Since the founding of the University of Limburg (1974), in The Netherlands, an innovative medical curriculum has been guided by educational principles of problem-

orientation, continuous assessment, student initiative and attitude development. The teaching of medical ethics was built into the preclinical curriculum from the start.

However, the clinical years remained largely unaffected, and only recently has an effort been made to extend the educational philosophy to this more or less traditional part of medical education. Within this context, an experiment of clinical ethics teaching was introduced in the Obstetrics and Gynaecology $(\mathrm{Ob} / \mathrm{Gyn})$ clerkships. The objectives, methods and results of this experimental programme are described in this paper. The success of the teaching is based on three features of the programme: 1) its student-centred approach;2) the programme is designed in a way similar to regular patient conferences; 3 ) the programme is taught by a team consisting of both clinician and ethicist. Before starting a longitudinal programme of ethics teaching during the clinical years, it proved very helpful to experiment with a well designed and evaluated pilot programme.

\section{Introduction}

Six out of eight medical faculties in The Netherlands have ethics courses in their curriculum. Four of these faculties have departments of medical ethics. Most of the medical ethics programmes have only fairly recently been introduced into the curricula, starting as optional but rapidly evolving into integrated and obligatory parts of medical education. Nearly all of these programmes offer introductory courses and are offered during the preclinical years. The number of ethics teachers involved in medical education is small. Although some of them have had teaching experience for more than a decade, data on programmes are scarce. Publications specifically concerning the objectives, design and evaluation of ethics courses have only recently appeared $(1,2)$. Even organisations such as the Dutch Society for Philosophy and Medicine, and

\section{Key words}

Medical ethics teaching; medical education. the Society of Ethicists give low priority to exchange of information on medical ethics teaching.

\section{A student-centred approach}

The situation in the University of Limburg is an exceptional one. The Medical Faculty was founded in 1974 as the first, and up to now unique, innovative medical curriculum in The Netherlands after the war. The programme is based on four educational principles: 1) the curriculum is problem-orientated; 2) there is a continuous assessment system; 3) students are motivated to take initiatives in gaining knowledge and mastering skills; 4) the curriculum focusses on the development of attitudes. Formal lectures and practical courses play only a minor role in the curriculum. The base mode of instruction is learning in small groups guided by a tutor, on the model of the Faculty of Medicine of McMaster University in Canada. This development of a completely new type of medical education and training gave the opportunity for the teaching of medical ethics to be incorporated into the curriculum from the start. The teaching of ethics in the early years has been described by Sporken (3). Since then many aspects of the curriculum have changed. Some of the innovative elements (for example problem-orientation and skills training) have been introduced into other medical faculties, whereas some of the more traditional teaching methods are allowed within the present Maastricht curriculum (for example lectures, practical courses, readers and readingassignments).

However, the basic principles are left untouched, so that the medical programme is still essentially studentcentred. One of the consequences of the programme is that medical ethics as a discipline is not easily identifiable for students within the curriculum. However, the same applies to every other discipline. The programme is structured in units (with an average duration of six weeks) with a specific theme, for example, Fever, Fatigue, Loss of blood, Back complaints. Learning during these units is stimulated by offering cases, problems and tasks with a set of predetermined goals and objectives, together with recommended literature and training programmes which are all included in a course book for each specific unit. This implies that ethical aspects are integrated, if 
possible, with other aspects of a clinical problem. Since students are relatively free in their choice of interests, they can concentrate exclusively, for example, on the study of surgical or pathological dimensions of the problem. On the other hand, they have several opportunities to follow optional courses, for example in ethics, during free units in the second, third, and fourth years.

Thus the output of the undergraduate programme can be very diverse: almost half of the students have ignored ethics completely, but still a third of the students have acquired quite a considerable knowledge of ethics.

At first the Maastricht innovation project affected mainly the preclinical programme (four years). Clinical education (two years) had virtually been untouched since the clinical part of the medical curriculum is supposed to be problem-based in itself. Recently a serious attempt has been made to introduce integrated learning methods into the traditional clerkships.

Part of this new development is the introduction of clinical ethics teaching which was started as an experiment in February 1987 in the ObstetricsGynaecology (Ob/Gyn) clerkship. Since the results of this experiment turned out to be excellent, clinical ethics teaching is now being introduced into other clerkships as well.

We describe here the objectives, scope and results of our clinical ethics conferences in the Department of Obstetrics and Gynaecology.

\section{Objectives}

The objectives of the programme are:

(i) to make students aware of the normative dimension of clinical decisions, so that

a. they are able to identify which aspects of decisions are technical in nature and which are ethical;

b. they are able to assess how technical and ethical aspects are related to each other.

(ii) to develop skills in analysing the normative dimension of clinical decisions (identifying moral principles and rules; critically analysing moral arguments)

(iii) to develop skills of exploring and justifying personal decisions regarding ethical issues as they arise in specific clinical contexts.

These objectives arise from the philosophical conception of clinical medicine as essentially a moral profession $(4,5)$. It is argued that medicine is a moral activity since it has a unique character as a healing relationship between doctor and patient. Value judgements and moral concerns are therefore often inseparable from the technical concerns of medicine both in correct diagnosis and in the best choice of treatment. Thus many clinical decisions have ethical components. The logical consequence of these ideas is that ethics is an inherent, second-order reflective function of medicine itself (6). If a normative dimension is intrinsic to medical practice itself, physicians have the duty to reflect on the moral quandaries of medicine. It is of course true that a transfer of the clinician's moral commitments and stance has always occurred in medical education, and in that sense students learn medical ethics in the clinic every day. So far, however, this transfer has on the whole been implicit and unreflective and has not taught the skills of analysis, criticism and justification of moral positions. Just as the technical dimensions of medical decisions are articulated and evaluated by means of, for example, clinical-pathological conferences or pre-operative case conferences, so the normative dimensions need also to be explored and evaluated. Common sense alone should indicate that education concerning most clinical decisions is inadequate if their normative aspects are not explored and discussed.

\section{Methods}

Every second Wednesday of the month from 1-2 pm there is an ethical conference for clinical students in the Ob/Gyn Department (seven - ten students). The design of the conference is identical to other clinical conferences in which the students usually participate. One of the students selects and presents a case, preferably a patient who had been examined by the student herself. A few days before the conference, relevant data are communicated to both commentators (a clinician and a medical philosopher). Each conference has the same procedure:

a) Presentation of the case by one of the students: relevant data and clinical findings are presented with the help of the overhead projector or a concise paper handed out at the start of the conference. Since only the main issues of the case need to be emphasised, this part of the conference takes only a few minutes.

The presentation ends with the student clarifying the reasons for his choice of this particular case. He does so by offering a preliminary answer to three questions:

1. What is, in your opinion, the moral problem in this case?

2. How would you deal with this problem (and how has it been resolved in practice)?

3. Why do you propose to deal with this problem in this way?

b) Clinical comments The most important medical aspects of the case are expounded by the attending clinician. He can explain the empirical evidence for the clinical judgement and illustrate the balancing of medical benefits and harms which is typical in comparable cases. $\mathrm{He}$ is also familiar with the diagnostic and therapeutic policies of his department. c) Ethical comments The moral dimensions of the case is clarified by the philosopher. He points out which moral values and principles may be involved in the case, and which are the crucial components of the moral dilemma(s), thus offering a first outline of the 'moral structure' of the case. 
d) Discussion This part of the conference is most important and takes the greater part of the available time. Students are invited (if necessary) to express their opinion on the case. In order to apply some structure to the discussion, a six-step process of moral reasoning (fig 1 ) is followed. This ethical workup (7) proceeds from facts to values and from weighing alternative decisions to justifying an actual decision. The first steps usually do not take much time since they have already been outlined in the comments. The discussion therefore focusses on the choice of a particular course of action (or criticism of the decisions made in practice) and on a defence of this course of action with moral arguments. It motivates students to explore their own attitudes to moral problems and to pay attention to the relationship between professional morality and their personal value system.

e) Summary and conclusion One of the commentators closes the conference with a summary of the moral problem(s), the lines of argumentation during the discussion and the preferable options in decision-making. Recommendations for further reading are made, and usually one or two appropriate and short publications (for example on confidentiality, autonomy or beneficence) are handed out to the participants.

f) Evaluation Directly after the conference students anonymously fill out an evaluation form which consists of a number of statements. The students are invited to express the extent of their (dis)agreement with each particular statement (on a five-point scale). A few statements concern their actual knowledge in the field of medical ethics. The others are evaluative statements on different aspects of the case and the conference. The responses to some of these items indicate to what extent the objectives of the clinical-ethics conference are realised, in the perception of the students.

\section{Results}

Although the conferences were not obligatory, they were attended by almost all students. The average number of participants was seven (minimum five; maximum ten). Every student had the opportunity to participate twice during the clerkship (eight weeks). The evaluation of 15 conferences (from February 1987 until July 1988) was excellent (fig 2).

The results indicate that the objectives were realised. The students acknowledged the relevancy of the case and the instructiveness of the conference (first objective). They strongly agreed with the statement that this kind of ethics teaching helps them to deal with moral problems (second objective). They also agreed (though less strongly) that the conferences teach them to understand and justify their personal approach to moral problems (third objective). The design of the conferences was also appreciated: according to 66 per cent of the students the duration of each conference (one hour) was perfect (for 31 per cent it was too short); according to 55 per cent the frequency of the conferences (once a month) was satisfactory (for 44 per cent it was too low). All but one participant preferred the co-operation of clinician and philosopher.

The questionnaires further made clear that the students' prior knowledge of medical ethics was indeed diverse: 43 per cent of the participants had never read any medical ethics books, 27 per cent had read one book, and 30 per cent two or more books.

Since the cases are selected by the students, the topics discussed at the conferences do not in any way represent the moral issues raised in gynaecology and obstetrics. Nonetheless after 15 conferences a certain pattern is detectable in the students' choices of clinical ethical problems. Characteristic of gynaecology and obstetrics is the continuous need to balance the interests of the woman, fetus and physician (and in

\section{Figure 1}

\section{The process of moral reasoning}

1. Facts:

2. Relevant values:

3. Major value conflicts

4. Possible courses of action

5. Choose a course of action

6. Defend this decision medical

social

psychological

physicians

patients

hospital

society

-decision-making

- criteria used

- underlying assumptions 


\section{Figure 2}

Clinical ethics - Evaluation (15 cases; 110 students)

5-point scale $5=$ strong agreement; $1=$ strong disagreement

* This kind of ethics teaching is appropriate

* The case is relevant to medical practice

* The conference is instructive

* The conference is in line with other clinical patient conferences

* This kind of ethics teaching helps me to deal with moral problems in the clinic

* The conference gives me a deeper understanding of my personal approach to moral problems

* The conference makes me understand how to provide good reasons to support my moral judgement on this particular case

some cases society). Although the list of medical topics brought to the conferences (fig 3) may at first glance seem rather diverse, the same ethical issues reappear in many cases. In general these issues are discussed in two steps:

a) Recognition of the relevant moral principles: autonomy, beneficence, confidentiality, sanctity of life, justice.

b) Determination of the major conflict(s) between principles, and analysis of arguments pro and con the conflicting principles.

This procedure does not offer students a synopsis of the body of ethical knowledge. However, it develops their ability to recognise and analyse ethical problems. This is consistent with the general objective of the Maastricht curriculum: problem-orientation, motivation to student initiative and development of attitudes.

\section{Figure 3}

Topics brought to clinical-ethical conferences by $\mathrm{Ob} / \mathrm{Gyn}$ students

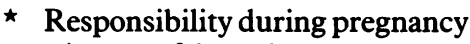

- in case of drug abuse

-in case of heroin-cocaine addition

* Saving the life of the child -in case of partus praematurus imminens

-in case of imminent intrauterine death

* Medical confidentiality

- and veneral disease

- and drug addition with pregnancy

* Non co-operative patients

* Prenatal diagnosis and abortion

* IVF and resource allocation in health care

* Indications for gynaecological surgery

- mutilating surgery for septuagenarian patients with vulva carcinoma

- hysterectomy for patients under thirty with minor complaints

* Responsibility for reproduction

- counselling on birth control

- criteria for sterilisation and refertilisation 


\section{Discussion and conclusions}

Our experiment to introduce monthly clinical-ethical conferences in the $\mathrm{Ob} / \mathrm{Gyn}$ clerkships was well received by the students. The objectives of the experiment were realised. We conclude this paper with a summary of the lessons we have learned from our project which may be of some use for others.

We agree with Southgate et al (8) on the advantages of a student-centred approach. It is very gratifying for students to play an active role in the educational process. Since they can select and present the case, and because there is ample time for discussion, students are motivated to clarify and re-think their ideas and preconceptions about moral issues. This motivation to initiative is in our opinion the first important factor contributing to the success of the conferences.

Second, the design of the programme contributed to its positive perception by the students. It is conducted similarly to the daily patient conferences that take place as a routine and generally accepted component of clinical work. However, such conferences are interposed between practical activities which always have priority. Time is limited; information must be to the point and closely fitted to the practical aspects of patient care. The theoretical pretensions of a participating philosopher, who is not used to this kind of succinct and fragmentary presentation, must be reduced.

Third, the co-operation of clinician and philosopher is essential. This has repeatedly been emphasised in other reports on clinical ethics teaching $(9,10)$. The fact that one of the leading clinicians is involved in the planning of the conference, that he is actually present at the conference and will even stress the importance of ethical issues in his daily practice, has a profound effect on the students' perception of the relevancy and appropriateness of medical ethics. In fact, the clinician is one of the professional role models for the clinical student, and his influence on future conduct surpasses anything ethicists can possibly do. Perhaps, in the long run the principal effect of ethical conferences will arise from teaching the teachers.

Fourth, before introducing any kind of ethics teaching into the clinical years, it is a matter of good policy to start with a carefully planned and designed pilot programme in one of the clinical settings. As a result of our experiment we now have more or less objective data and systematised experiences to convince the Faculty Committee responsible for clinical education, as well as clinicians in other departments, of the feasibility, relevance, and usefulness of ethical conferences. This is a way to obtain widespread and official support for introducing clinical ethics teaching into most of the clerkships. This introduction will allow supplementation of the current objectives with cognitive ones including perhaps the specification of a set of topics that ought to be covered during an ethics programme. A regular sequence of ethical conferences during the clinical years makes it possible to design a longitudinal programme, at the end of which every student has a basic understanding of relevant ethical concepts and positions.

$H A M f$ ten Have $M D, P h D$ is a physician and philosopher, and Professor in the Department of Health Care Ethics and Philosophy at Limburg University, $P O$ Box 616, 6200 MD Maastricht, The Netherlands. G M $M$ Essed $M D$ is a gynaecologist, Associate Professor of Obstetrics and Gynaecology, and Professor of Clinical Education at Limburg University.

\section{References}

(1) Have $\mathrm{H}$ ten, Arend $\mathrm{A}$ van der. Philosophy of medicine in The Netherlands. Theoretical medicine 1985; 6:1-42.

(2) Have H ten, Kimsma G K. Medisch-ethisch onderwijs in de Verenigde Staten en in Nederland. Ned tijdschr geneeskd 1987; 131:1447-1449.

(3) Sporken P. The teaching of medical ethics in Maastricht, The Netherlands. Fournal of medical ethics $1975 ; 1: 181-183$.

(4) Cassell E J. The healer's art. A new approach to the doctorpatient relationship. Philadelphia: Lippincott, 1976.

(5) Pellegrino E D, Thomasma D C. A philosophical basis of medical practice. New York, Oxford: OUP, 1981.

(6) Thomasma DC. Legitimate and illegitimate roles for the medical ethicist. In: Ackerman T F et al, eds. Clinical medical ethics. Lanham: University Press of America, 1987: 83-94.

(7) Thomasma D C. Training in medical ethics: an ethical workup. Forum on medicine 1978: 68-71.

(8) Southgate L J, Heard S R, Toon P D, Salkind M R. A student-led approach to teaching. Fournal of medical ethics 1987; 13:139-143.

(9) Calman K C, Downie R S. Practical problems in the teaching of ethics to medical students. Fournal of medical ethics 1987; 13:153-156.

(10) Arnold R M, Forrow L, Wartman S A, Teno J. Teaching clinical medical ethics: a model programme for primary care residency. Fournal of medical ethics 1988; 14:91-96. 